\title{
Effect of temperature and stress on molecular structure and carbon monoxide generation of lignite from Kailuan mining area
}

\author{
Xiao Cangyan ${ }^{1, *}$, Wei Chongtao ${ }^{1}$, Guo Li wen ${ }^{2}$, Shen Jian ${ }^{1}$ \\ ${ }^{1}$ Key Laboratory of Coalbed Methane Resources \& Reservoir Formation Processes, Ministry of Education, School of Resources and \\ Earth Science, China University of Mining and Technology, Xuzhou 221008, China; \\ ${ }^{2}$ North China Institute of Aerospace Engineering, Langfang 065000, China
}

Abstract: In order to analyze the origin of carbon monoxide (CO) in coal seams, stress-strain experiments under temperature of 50, 150 and $250{ }^{\circ} \mathrm{C}$ were conducted using lignite from Kailuan mining area. Fourier transform infrared spectroscopy and elemental analysis were carried out before and after deformation of the samples. The results indicated that $\mathrm{CO}$ generated at 150 and $250{ }^{\circ} \mathrm{C}$; the gas component was mostly oxygen $\left(\mathrm{O}_{2}\right)$, with small amount of carbon dioxide $\left(\mathrm{CO}_{2}\right)$, methane $\left(\mathrm{CH}_{4}\right)$ and hydrogen $\left(\mathrm{H}_{2}\right)$. At $50{ }^{\circ} \mathrm{C}$, $\mathrm{O}_{2}$ and a little $\mathrm{CO}_{2}$ were observed and no $\mathrm{CO}$ was found. The carbon content of the coal samples increased slightly after deformation, and the oxygen content, $\mathrm{H} / \mathrm{C}$ ratio, and $\mathrm{O} / \mathrm{C}$ ratio decreased. The molecular structure of coal displayed different evolution characteristics at various temperatures. At 50 and $150{ }^{\circ} \mathrm{C}$, the falling off of side chains, broken of ether bond and directional realignment of the aliphatic chains resulting in the formation of long chains were the main performance of coal molecular structure evolution. While at $250{ }^{\circ} \mathrm{C}$, the side chains fell off and short chains formed. Furthermore, at both 150 and $250{ }^{\circ} \mathrm{C}$, condensed degree of aromatic ring increased. Under the action of temperature and pressure, $\mathrm{CO}$ forms in two ways. The first is that ether bond breaks, oxygen and carbon atoms combine together and forms $\mathrm{CO}$, or $\mathrm{O}_{2}$ forming in the broken of ether-oxygen bond leads to the oxidation of free radicals and resulting in the formation of $\mathrm{CO}$. And the second is that $\mathrm{CO}$ derives from falling off of $\mathrm{C}=\mathrm{O}$ group.

Keywords: Lignite; Molecular structure; Carbon monoxide generation; Deformation; Temperature

\section{Introduction}

Coal, one kind of organic rock, is very sensitive to temperature and pressure. In the process of the geological evolution, various tectonic-thermal events inevitably lead to a series of physical and chemical changes of coal. Aromatic structure, aliphatic structures, as well as oxygen containing functional groups in coal molecular structure perform different evolution characteristics, along with the generation of some kind gases. By employing fourier transform infrared spectroscopy (FTIR), X-ray diffraction (XRD), and X-ray photoelectron spectroscopy (XPS) methods to study the molecular structure of tectonic deformation coal, some researchers considered that tectonic deformation coal and primary structure coal with the same metamorphic degree are different in their chemical structure [1-10].

In recent years, carbon monoxide (CO) over safty standard has been detected from an increasing number of coal mines in China. Research shows that the origin of $\mathrm{CO}$ is not only due to the oxidation of coal in the open air, but also due to the primary deposition of $\mathrm{CO}$ in the coal seam [10,11]. Coal pyrolysis experiments show that $\mathrm{CO}$ is produced when the pyrolysis temperature reaches $300-800{ }^{\circ} \mathrm{C}$ [11]. $\mathrm{CO}$ is also produced in deformation experiments at temperature of $200^{\circ} \mathrm{C}$ [12]. However, it is still not clear whether the original occurrence of $\mathrm{CO}$ in coalbed is caused by the side chain rupture of molecular structure at certain temperature at present.

In the past, deformation experiments at high temperatures and pressures usually concentrated on temperature, pressure, and strain rate. However, the chemical changes in the molecular structure has not been systematically studied in those experiments, and whether or not $\mathrm{CO}$ has been generated during the process of deformation have been received little attention in those experiments. In this study, coal samples were collected from the Cuijiazhai Coal Mine of the Kailuan Mining Group, where CO concentration has once exceeded the safety limitation during the year of 2012. The deformation experiments were performed at temperatures 50,150 , and $250{ }^{\circ} \mathrm{C}$. The evolution of coal molecular structure and the CO generation mechanism has been studied. And the purpose of this is to find the origin of $\mathrm{CO}$ and provide a theoretical basis for the coal mining safety.

\section{Experimental}

\subsection{Sample collection and preparation}

Samples in the study were obtained from E11510 working face of the Cuijiazhai Coal Mine, at depth of 835 $\mathrm{m}$. Three columns with $40 \mathrm{~mm}$ length and $20 \mathrm{~mm}$ diameter were prepared. Then, following the national standard "GB474-2000", the remained samples were crushed and splited for elemental, macerals component and industrial analysis, and for the measurement of vitrinite reflectance.

\subsection{Stress-strain experiment}

Experiments were conducted by using a high temperature and high pressure apparatus, which belongs to the institute of geology, China Earthquake Administration. The temperature was controlled by a set of device, which was used to adjust the power of the heating furnace. To ensure uniform pressure and safe heating of the samples, argon gas was used to apply the confining pressure. And the axial load was controlled with a digital hydraulic servo.

Firstly, $30 \mathrm{~min}$ of vacuating was conducted, and then $20 \mathrm{MPa}$ confining pressure was applied. The

Received 10 September 2015; revised 29 November 2015; accepted 20 January 2016

* Corresponding author. Tel.: +86 13852002375

E-mail address: weighct@163.com 
airtightness was detected. If the entire system was completely sealed, another 15 min of vacuating was applied. Secondly, let the system heating be the experiment temperature. The heating rate was set at $5{ }^{\circ} \mathrm{C}$ per minute. After the temperature reached the desired value, the experimental confining pressure was set to $30 \mathrm{MPa}$. Thirdly, the axial pressure was added. The axial deformation rate was set to $0.001 \mathrm{~mm}$ per second until the deformation displacement reached 3-3.5 mm, then kept the temperature at 50,150 and $250{ }^{\circ} \mathrm{C}$, deformation and axial pressure were stable for $7 \mathrm{~h}$ and ended the experiment. During the experiment, the temperature was strictly controlled to ensure the accuracy of the experimental results. Meanwhile, a vacuum bag was used to collect the gas generated in the process of deformation. The deformed samples were broken and ground to 200 mesh for infrared spectroscopy and elemental analysis. The detection of gas composition was performed in the Beijing Coal Chemical Research Branch of the China Coal Science and Technology Research Institute, using an Agilent 7890 meteorological chromatograph.

\subsection{Fourier transform infrared spectroscopy}

A Vertex 70 Fourier transform infrared spectrometer of Bruker Dalton was used in the infrared spectrum analysis. Each sample was cut into thin slices with a diameter of about $13 \mathrm{~mm}$. For the test sample, $\mathrm{KBr}$ ratio was $1: 160$, in the range of $400-4000 \mathrm{~cm}^{-1}$ for collecting spectral information, and the resolution was $4 \mathrm{~cm}^{-1}$. FTIR spectrum was obtained after 32 cumulative scans. In addition, the above experiment was conducted for both samples before and after stress-strain experiments.

\section{Results analysis}

\subsection{Coal quality}

The values listed in Table 1 show that the sample represents a low-degree metamorphism of lignite. Table 1 Coal quality data

\begin{tabular}{|c|c|c|c|c|c|c|c|c|c|c|c|c|c|}
\hline \multirow{2}{*}{ Sample } & \multicolumn{3}{|c|}{ Industrial analysis ( $\%$, by weight) } & \multicolumn{5}{|c|}{ Elemental analysis (\%, by weight) } & \multicolumn{4}{|c|}{ Maceral composition ( $\%$, by weight) } & \multirow{2}{*}{$R_{0}(\%)$} \\
\hline & $\mathrm{M}_{\mathrm{ad}}$ & $A_{d}$ & $\mathrm{~V}_{\mathrm{daf}}$ & $\mathrm{C}_{\mathrm{daf}}$ & $\mathrm{H}_{\text {daf }}$ & $\mathrm{O}_{\text {daf }}$ & $\mathrm{N}_{\text {daf }}$ & $\mathrm{S}_{\mathrm{daf}}$ & $\mathrm{V}$ & I & $\mathrm{E}$ & M & \\
\hline $\mathrm{CJZ}$ & 18.36 & 5.54 & 55.58 & 73.14 & 4.38 & 21.31 & 0.86 & 0.31 & 47.37 & 38.21 & 0.78 & 13.64 & 0.41 \\
\hline
\end{tabular}

\subsection{Deformation feature and gas composition}

In order to analyze the molecular structure changes of the sample under different temperatures, the deformation experiments were performed at 50,150 , and $250^{\circ} \mathrm{C}$. Fig. 1 shows the results of the experiments.

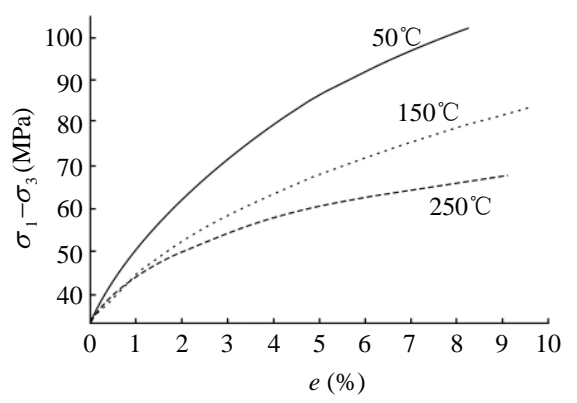

Fig. 1. Strain curves of the deformation experiments at different temperatures

To ensure purity of the collected gas, the impact of the air and gas adsorbed in coal were minimized. Before the experiment, the air collecting-bag was connected directly to the experimental equipment. And it was vacuumed through the vacuum system together with the whole system simultaneously. Coal samples were kept under vacuum state and significant amount of adsorbed gas was desorbed, and only little part of the adsorbed gas in the confined pores was difficult to expel. This little amount of adsorbed gas had insignificant effect on the experimental results, thus the collected gas mostly came from the deformation experiment. The gases detected in the experiment are listed in Table 2.

Table 2 Composition of gases generated in the deformation experiment (\%, by volume)

\begin{tabular}{llllllllll}
\hline Sample number & $\mathrm{H}_{2}$ & $\mathrm{CO}_{2}$ & $\mathrm{C}_{3} \mathrm{H}_{8}$ & $\mathrm{C}_{3} \mathrm{H}_{6}$ & $\mathrm{C}_{2} \mathrm{H}_{4}$ & $\mathrm{C}_{2} \mathrm{H}_{6}$ & $\mathrm{O}_{2}$ & $\mathrm{CH}_{4}$ & $\mathrm{CO}$ \\
\hline $50^{\circ} \mathrm{C}$ & 0 & 4.6499 & 0 & 0 & 0 & 0 & 95.3501 & 0 & 0 \\
$150^{\circ} \mathrm{C}$ & 0.0052 & 17.4538 & 0.0428 & 0.0013 & 0.0311 & 0.0907 & 81.4745 & 0.311 & 0.5896 \\
$250^{\circ} \mathrm{C}$ & 0.0952 & 97.5516 & 0.0732 & 0.0084 & 0.0387 & 0.0774 & 0.7630 & 1.2816 & 0.1109 \\
\hline \multicolumn{7}{l}{ Note: $\mathrm{N}_{2}$ and $\mathrm{O}_{2}$ have been deduced according to the proportion of $\mathrm{N}_{2}$ and $\mathrm{O}_{2}$ in the air. }
\end{tabular}

The values listed in Table 2 indicate that $\mathrm{CO}$ is not collected at $50^{\circ} \mathrm{C}$; and $\mathrm{CO}$ is collected at both 150 and $250{ }^{\circ} \mathrm{C}$. Similar performance is observed for other gases, such as $\mathrm{H}_{2}$ and $\mathrm{CH}_{4}$. Other observations show that the concentration of $\mathrm{O}_{2}$ content is the highest at 50 and $150^{\circ} \mathrm{C}$, while the $\mathrm{CO}_{2}$ concentration is the highest at $250{ }^{\circ} \mathrm{C}$. 


\subsection{Elemental analysis}

Coal is mainly composed of five elements: carbon, hydrogen, oxygen, nitrogen and sulfur. Carbon is of the highest concentration of all elements in coal. Carbon is mainly present as aromatic nucleus and aliphatic side chains, such as $\mathrm{C}-\mathrm{C}, \mathrm{C}-\mathrm{O}$, and $\mathrm{C}-\mathrm{H}$ bonds. Hydrogen is also present in coal mainly as $\mathrm{C}-\mathrm{H}$ bonds. Oxygen in coal is represented by molecular bridge bonds and functional groups, mainly in the form of $\mathrm{C}-\mathrm{O}, \mathrm{COO}$, and $\mathrm{C}=\mathrm{O}$ bonds In order to analyze the effect of deformation on the coal macromolecular composition, elemental analysis of the deformed samples was performed.

Elemental analysis before and after deformation was performed using an Elementar Vario MACRO Cube test at the Chemical Engineering Department of the China University of Mining and Technology (Table 3).

\begin{tabular}{llllll}
\hline \multicolumn{5}{l}{ Table 3 Analysis of the elements in coal before and after deformation (\%, by weigh } \\
\hline Sample & $\mathrm{C}_{\text {daf }}$ & $\mathrm{H}_{\text {daf }}$ & $\mathrm{O}_{\text {daf }}$ & $\mathrm{O} / \mathrm{C}$ & $\mathrm{H} / \mathrm{C}$ \\
\hline Undeformed coal & 73.14 & 4.38 & 21.31 & 0.29 & 0.06 \\
$50^{\circ} \mathrm{C}$ & 75.28 & 4.33 & 19.45 & 0.26 & 0.06 \\
$150^{\circ} \mathrm{C}$ & 75.84 & 3.97 & 19.24 & 0.25 & 0.05 \\
$250{ }^{\circ} \mathrm{C}$ & 76.96 & 3.98 & 18.12 & 0.24 & 0.05 \\
\hline
\end{tabular}

Deformation led to the increase in the carbon content of all three samples; however, the oxygen content decreased. The percentage of $\mathrm{O}$ reduces, which leads to a material basis for the collection of $\mathrm{CO}$ and $\mathrm{O}_{2}$ during the experiment. This indicated the formation of the oxygen gas as a result of the deformation.

The $\mathrm{C} / \mathrm{H}$ atom ratio in coal is 3:2 (Table 1), which is greater than the ratio 1:1 in the benzene ring. This value of ratio indicates that the aromatic structure, with at least two substituents on the benzene ring, represents the main part of the coal molecular structure. Moreover, the aliphatic structure, with the average of three substituents, is relatively less, indicating the presence of many aliphatic side chains in coal macromolecular structure.

Compared to undefromed coal, the $\mathrm{O} / \mathrm{C}$ ratios decreased at $50{ }^{\circ} \mathrm{C}$ while $\mathrm{H} / \mathrm{C}$ ratio kept stable. $\mathrm{O}_{2}$ and a small amount of $\mathrm{CO}_{2}$ were collected, which might be attributed to that after the falling off of the oxygen atom from oxygen containing functional groups, carbon atoms combined directly with each other to form $\mathrm{C}-\mathrm{C}$ bonds, resulting in $\mathrm{O} / \mathrm{C}$ decrease. And only small amount aliphatic side chains $-\mathrm{CH}_{3}$ and $-\mathrm{CH}_{2}$ were broken, which resulted in the stable of $\mathrm{H} / \mathrm{C}$ ratio.

At 150 and $250{ }^{\circ} \mathrm{C}$, the $\mathrm{O} / \mathrm{C}$ and $\mathrm{H} / \mathrm{C}$ ratios decreased, and $\mathrm{H}_{2}$ was collected, which might be caused by the dehydrogenation of aromatic structure. Hydrocarbon gases such as $\mathrm{CH}_{4}$ were probably produced as a result of the partly falling off of aliphatic side chains. At these two temperatures, the contents of $\mathrm{CO}_{2}$ and $\mathrm{CO}$ were different, a consequence caused by different amounts of $\mathrm{C}-\mathrm{O}, \mathrm{C}=\mathrm{O}$, and $\mathrm{COOH}$ functional groups in coal.

\subsection{Fourier transform infrared}

\subsubsection{Fourier transform infrared spectrum}

Fig. 2 shows the FTIR spectra of the samples before and after the deformation. The absorption peak at 3212 $\mathrm{cm}^{-1}$ is the stretching vibration of the aliphatic hydrogen-bonded association and aromatic OH. Peak at $2906 \mathrm{~cm}^{-1}$ is attributed to the stretching vibration of aliphatic $\mathrm{CH}$ and $\mathrm{CH}_{3}$. The peak at $2831 \mathrm{~cm}^{-1}$ corresponds to the stretching vibration of $\mathrm{CH}_{2}$. Peak observed at $1690 \mathrm{~cm}^{-1}$ is the $\mathrm{C}=\mathrm{O}$ stretching vibration of unsaturated carboxylic acid, and at $1579 \mathrm{~cm}^{-1}$ is the stretching vibration peak of hydrogen bond associated with $\mathrm{C}=\mathrm{O}$ or aromatic skeleton $\mathrm{C}=\mathrm{C}$. Peak at $1330-1110 \mathrm{~cm}^{-1}$ corresponds to the stretching vibration of phenol, ether, and alcohol. Peaks at 870,815 , and $750 \mathrm{~cm}^{-1}$ are attributed to 2,3 , and 4 hydrogen deformation vibration of the same aromatic nucleus of aromatics [13].

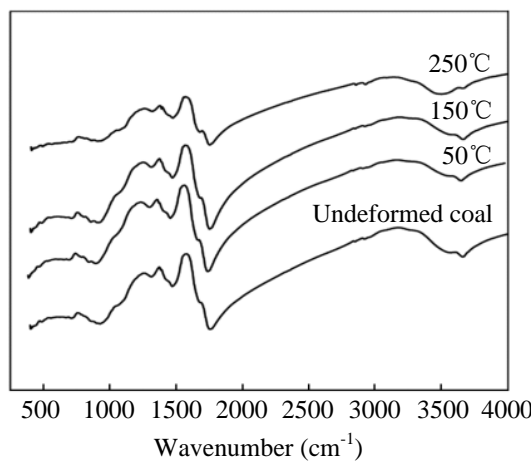

Fig. 2. Infrared spectra of the samples at different temperatures

Compared to undeformed coal, no variation takes place for the peak numbers and peak shape of the FTIR spectra, indicating that the kind of functional group in coal molecular structure keeps stable. And the intensity 
changes at different temperatures reflect that the deformation causes changes in the content or number of them. 3.4.2 Qualitative and semi-quantitative analysis

Different concentration of sample may lead to different peak intensities. To reduce this error, base-line correction and normalization processing of the spectrum were performed in this study [14]. The FTIR peaks locating at $3000-3600 \mathrm{~cm}^{-1}$ correspond to the hydroxyl group, and those at $2800-3000 \mathrm{~cm}^{-1}$ attribute to aliphatic hydrocarbon, those at $1000-1800 \mathrm{~cm}^{-1}$ are ascribed to oxygen containing functional groups, and those at 700-900 $\mathrm{cm}^{-1}$ correspond to the aromatic $\mathrm{CH}$ outside surface deformation and vibration. In order to analyze the origin of $\mathrm{CO}$ and the changes in aliphatic structure during the experiment, only oxygen containing functional groups and aliphatic hydrocarbons were analyzed here. Fig. 3 shows the proceeding FTIR spectrum.

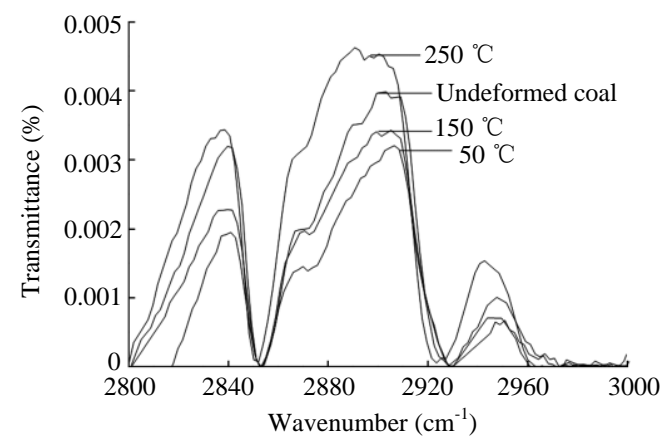

(a) Aliphatic hydrocarbons

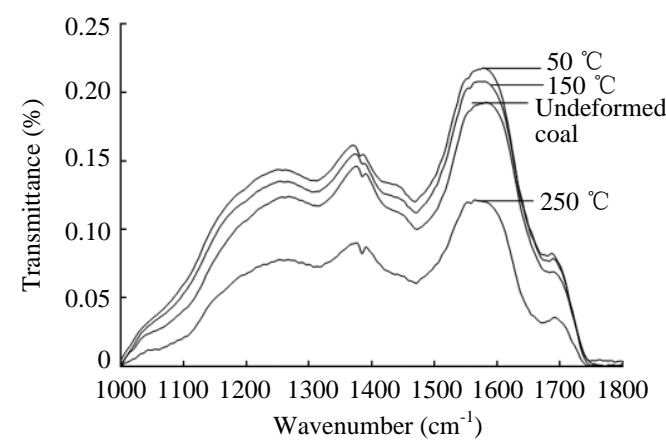

(b) Oxygen containing functional groups

Fig. 3. Process of FTIR spectrum

Fig. 3 shows that after deformation, the aliphatic hydrocarbons and the oxygen containing functional groups are characterized by different peak intensities and shapes at various temperatures. The highest peak intensity of the aliphatic hydrocarbons is observed at $250{ }^{\circ} \mathrm{C}$. The intensity decreases in the order of undeformed coal, 150 and $50{ }^{\circ} \mathrm{C}$. The peaks for the oxygen functional groups perform a reverse order, and the highest intensity is observed at $50{ }^{\circ} \mathrm{C}$. And the intensity decreases from $150{ }^{\circ} \mathrm{C}$ to undeformed coal then to $250{ }^{\circ} \mathrm{C}$

In this study, the software origin was used to perform peak fitting (using Gaussian distribution) [14]. The contents of the functional groups before and after deformation at three temperatures are listed in Table 4.

Table 4 Content functional groups $\left(\mathrm{cm}^{-1}\right)$

\begin{tabular}{lllllll}
\hline Peak & 1579 & 2944 & 2906 & 2831 & 1703 & $1330-1110$ \\
\hline Undeformed coal & 29.831 & 0.017 & 0.059 & 0.080 & 2.021 & 33.00299 \\
$50{ }^{\circ} \mathrm{C}$ & 32.539 & 0.012 & 0.057 & 0.042 & 2.203 & 35.27863 \\
$150^{\circ} \mathrm{C}$ & 33.631 & 0.013 & 0.063 & 0.063 & 2.198 & 34.06171 \\
$250{ }^{\circ} \mathrm{C}$ & 14.369 & 0.030 & 0.066 & 0.811 & 1.925 & 10.40158 \\
\hline
\end{tabular}

The molecular structures of the samples are different at three temperatures. At $250{ }^{\circ} \mathrm{C}$, the intensity of peak at $1579 \mathrm{~cm}^{-1}$ decreases and the same results have also been reported [15]. This means that $\mathrm{C}=\mathrm{O}$ of hydrogen bonds content decreases [13]. While at 50 and $150{ }^{\circ} \mathrm{C}$, the intensity of the same peak increases slightly compared to undeformed coal, similar phenomenon was reported [3]. At 50 and $150{ }^{\circ} \mathrm{C}$, the impact of the temperature and pressure to $\mathrm{C}=\mathrm{O}$ of hydrogen bonds is small, alone with the broken of aliphatic side trains, will lead to relative increase of $\mathrm{C}=\mathrm{O}$ of hydrogen bonds content after deformation, and the increasing of peak intensity [13].

3.4.3. Infrared structure parameter

During the infrared analysis of coal, the sample thickness and experimental temperature will affect the intensity of the infrared spectrum. In order to eliminate the influence of these two factors, peak intensity ratios (peak ratios or peak height ratios) is adopted to illustrate the characteristics and changes of various coal structures. The reason of doing this is that the peak areas of the FTIR spectrum are affected less by sample and instrument then peak height [14]. In this study, the peak area ratio $\left(I_{1}-I_{5}\right.$ in Table 5) were used for quantitative analysis of the microstructure of coal $[14,16,17]$. In Table $5, I_{1}=A 2944 / A 1579$ (where $A$ represents the area of certain peak, the number after it represents the wavenumber of the peak, same as below) represents the degree of the falling off of $\mathrm{CH}_{3} ; I_{2}=A 2831 / A 1579$ represents the degree of the falling off of $\mathrm{CH}_{2} ; I_{3}=A 2924 / A 2964$ characterizes aliphatic chain length and branched degree, the larger the $I_{3}$, the longer the aliphatic chain and the less the branched degree is; $I_{4}=(A 1703+1745) / A 1579$ characterizes of the relative content of oxygen containing functional groups $\mathrm{C}=\mathrm{O}$ and aromatic hydrocarbons; and $I_{5}=(A 1330-A 1110) / A 1579$ characterizes the relative content of C-O and the aromatic 
hydrocarbons.

The results of the quantitative peak area analysis are listed in Table 5.

Table 5 Infrared structure parameters

\begin{tabular}{llllll}
\hline Sample & $I_{1}$ & $I_{2}$ & $I_{3}$ & $I_{4}$ & $I_{5}$ \\
\hline Undeformed coal & 0.0006 & 0.0027 & 3.4706 & 0.0678 & 1.1063 \\
$50{ }^{\circ} \mathrm{C}$ & 0.0004 & 0.0013 & 4.7500 & 0.0677 & 1.0842 \\
$150^{\circ} \mathrm{C}$ & 0.0004 & 0.0019 & 4.8462 & 0.0653 & 1.0128 \\
$250{ }^{\circ} \mathrm{C}$ & 0.0021 & 0.0564 & 2.2000 & 0.1340 & 0.7239 \\
\hline
\end{tabular}

Table 5 shows that $I_{1}$ and $I_{2}$ are lower at 50 and $150{ }^{\circ} \mathrm{C}$ compared to the undeformed coal, indicating that the aliphatic side chains are broken off. The lack of hydrocarbon gases, such as $\mathrm{CH}_{4}$, which were not collected at $50{ }^{\circ} \mathrm{C}$, indicates that the aliphatic side chains may exist in the form of free radicals. The values of $I_{1}$ and $\mathrm{I}_{2}$ increase at $250^{\circ} \mathrm{C}$, which may be attributed to the formation of the short chains by the broken of the aliphatic side chains due to the action high temperature.

At 50 and $150{ }^{\circ} \mathrm{C}, I_{3}$ increases relative to undeformed coal, which may be due to the broken of the C-O bond, resulting in the falling off of oxygen atom and leading to the formation of some small molecules, such as $\mathrm{O}_{2}, \mathrm{CO}$, and $\mathrm{CO}_{2}$. Moreover, $\mathrm{C}-\mathrm{C}$ bond is also formed at the same time. At $250{ }^{\circ} \mathrm{C}$, decrease of $\mathrm{I}_{3}$ demonstrates the shortening aliphatic side chains, and the increase in the content of side chains.

$I_{4}$ refers to the process of falling off of the carboxyl and carbonyl of the coal macromolecular structure [18]. At $50^{\circ} \mathrm{C}$, almost no change is observed; this means that the temperature and pressure have less impact on it. At $150{ }^{\circ} \mathrm{C}, I_{4}$ decreases slightly, which means that carboxyl and carbonyl begin to fall off. At $250{ }^{\circ} \mathrm{C}$, it increases relative to undeformed coal and accompanying with relatively large amount of $\mathrm{CO}_{2}$ and $\mathrm{H}_{2}$ generation, because of stronger condensation of aromatic ring, and significantly influences of $\mathrm{C}=\mathrm{O}$ on the spectral peak. Another possibility is that $\mathrm{O}_{2}$ generated during the deformation can not be released timely and combines with carbon atoms to from carboxyl groups, leading to the increase of the $\mathrm{C}=\mathrm{O}$ group content [15].

Under the three temperature conditions, $I_{5}$ is lower than that of undeformed coal, indicating that the effect of temperature and pressure on $\mathrm{C}-\mathrm{O}$ of phenol, alcohol, and ether is significant, thus, the oxygen atoms of the oxygen-containing gas may partly come from the breaking of $\mathrm{C}-\mathrm{O}$ bond.

The analysis mentioned above shows that the molecular structure evolution of coal is different under different temperature conditions. The $\mathrm{C}-\mathrm{O}$ bond breaks to different degrees while the temperature is 50,150 and $250{ }^{\circ} \mathrm{C}$, respectively. At 50 and $150{ }^{\circ} \mathrm{C}$, aliphatic side chains fall off and rearrangement occurs, leading to the formation of a directional long chain. While at $250{ }^{\circ} \mathrm{C}$, aliphatic side chains fall off, and a short-chain structure is formed. And at 150 and $250^{\circ} \mathrm{C}$ conditions, the degree of condensation of aromatic ring increases.

\section{Generation of $\mathrm{CO}$}

Molecular structure of coal is extremely sensitive to stress. Under the influence of temperature and pressure, bridge bond, aliphatic side chains connected to the coal molecular skeleton, and oxygen containing functional groups may break off easily in the process of deformation. And a certain amount of hydrocarbons will be generated and released in the process [5].

In the process of deformation, the differential stress will acts on the coal molecular structure in the form of mechanical force or kinetic energy. The C-O bond is easy to be broken, the oxygen content is reduced compared to undeformed coal, and $I_{5}$ is also reduced. This indicates that the oxygen in the gas generated may be derived from the broken of $\mathrm{C}-\mathrm{O}$ bond. At 150 and $250{ }^{\circ} \mathrm{C}$, there exists $\mathrm{CO}$ in the gas generated and it is absent at $50{ }^{\circ} \mathrm{C}$, these indicates that $\mathrm{CO}$ may originate from oxygen atoms in $\mathrm{C}-\mathrm{O}$ combining with the carbon atoms of the aliphatic hydrocarbon radicals. However, at low temperature, i.e., $50{ }^{\circ} \mathrm{C}$, sufficient energy required for the formation of $\mathrm{CO}$ is not present.

At $50{ }^{\circ} \mathrm{C}, I_{4}$ decreases a little, and the gas contains a small amount of $\mathrm{CO}_{2}$, which may originate from $\mathrm{COOH}$. While at $150{ }^{\circ} \mathrm{C}$, further decrease of $I_{4}$ takes place, which indicates the broken of $\mathrm{C}=\mathrm{O}$ and the formation of $\mathrm{CO}$. And at $250{ }^{\circ} \mathrm{C}, I_{4}$ relatively increases, and the $\mathrm{CO}$ content in the gas generated is $0.1109 \%$, lower than that at $150{ }^{\circ} \mathrm{C}(0.5896 \%)$. As the influence of $\mathrm{C}=\mathrm{O}$ on the intensity of peak at $1579 \mathrm{~cm}^{-1}$ is significant, it is considered that less decrease of $\mathrm{C}=\mathrm{O}$, resulting in the lower content of $\mathrm{CO}$ at $250^{\circ} \mathrm{C}$

The analysis mentioned above shows that $\mathrm{CO}$ forms in two ways during the deformation. The first is that ether bond breaks, oxygen and carbon atoms combine together and forms $\mathrm{CO}$, or $\mathrm{O}_{2}$ forming in the broken of aether-oxygen bond leads to the oxidation of free radicals, resulting in the formation of $\mathrm{CO}$. And the second is that $\mathrm{CO}$ derives from falling off of $\mathrm{C}=\mathrm{O}$ group.

The process of $\mathrm{CO}$ generation is shown in Fig. 4. 


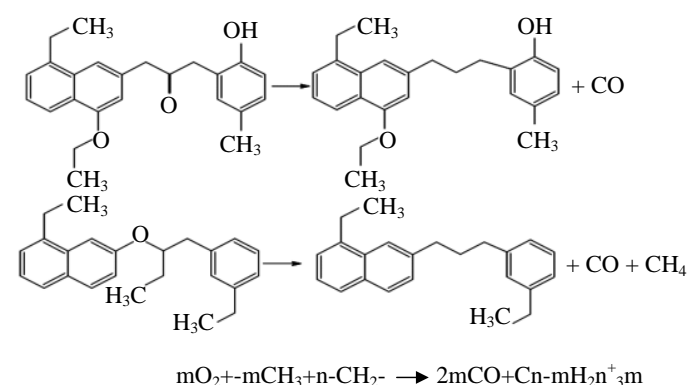

\section{Conclusions}

Fig. 4. Process of $\mathrm{CO}$ generation

From the analysis mentioned above, following conclusions are obtained.

(1) The lignite sample was collected from Cuijiazhai Coal Mine. Deformation causes an increase in the relative content of carbon, and a decrease of oxygen, and $\mathrm{H} / \mathrm{C}$ and $\mathrm{O} / \mathrm{C}$ ratios. $\mathrm{O}_{2}$ and $\mathrm{CO}_{2}$ are formed at three temperature conditions $\left(50,150\right.$, and $250{ }^{\circ} \mathrm{C}$ ), $\mathrm{CO}$ is produced at 150 and $250{ }^{\circ} \mathrm{C}$, along with $\mathrm{CH}_{4}, \mathrm{C}_{2} \mathrm{H}_{4}, \mathrm{H}_{2}$, and other hydrocarbon gases.

(2) The characteristics of the coal molecular structure evolution process vary under different temperature conditions. At 50 and $150{ }^{\circ} \mathrm{C}$, the molecular structure of the aliphatic side chains and the ether bonds break, and the molecular structure rearrange to form a long directional chain. At $250{ }^{\circ} \mathrm{C}$, the aliphatic side chains break off and form a short-chain structure. At 150 and $250^{\circ} \mathrm{C}$, aromatic rings are formed.

(3) $\mathrm{CO}$ is produced forms in two ways during the deformation. The first is that ether bond breaks, oxygen and carbon atoms combine together and forms $\mathrm{CO}$, or $\mathrm{O}_{2}$ forming in the broken of ether-oxygen bond leads to the oxidation of free radicals and resulting in the formation of $\mathrm{CO}$. And the second is that $\mathrm{CO}$ derives from falling off of $\mathrm{C}=\mathrm{O}$ group.

\section{Acknowledgments}

The authors acknowledge the financial support from the National Science foundation of China (No.41430317), the Discipline Innovative Engineering Plan sponsored by the Ministry of Education of China and the State Administration of Foreign Experts Affairs of China (No.13023), and the Priority Academic Program Development of Jiangsu Higher Education Institutions.

\section{References}

[1] Ju YW, Lin H, Li XS, Fan JJ. Tectonic deformation and dynamic metamorphism of coal. Earth Science Frontiers 2009;16(1):158-166.

[2] Guo ZB, Jiang YL, Pang JW, Liu JW. Distribution of ground stress on Puhe Coal Mine. International Journal of Mining Science \& Technology 2013;23(5):139-143.

[3] Hou QL, Li HJ, Fan JJ, Ju YW, Wang TK, Li XS, Wu YD. Structure and coalbed methane occurrence in tectonically deformed coals. Science China Earth Sciences 2012;55(11):1755-1763.

[4] Xu RT, Li HJ, Guo CC, Hou QL. The mechanisms of gas generation during coal deformation: Preliminary observations. Fuel 2014; 117(5): 326-330.

[5] Cao DY, Li XM, Zhang SR. Influence of tectonic stress on coalification: stress degradation mechanism and stress poly condensation mechanism. Sci China Ser D-Earth Sci 2007;50(1):43-54.

[6] Pan JN, Hou QL, Ju YW, Bai HL, Zhao YQ. Coalbed methane sorption related to coal deformation structures at different temperatures and pressures. Fuel 2012;102(3):760-765.

[7] Li XM, Cao DY, Liu DM. Structure of different types of coal metamorphism by HTEM. Ming Science \& Technology 2010;20(6):835-838.

[8] Feng J, Li WY, Xie KC. Research on coal structure using FTIR. Journal of China University of Mining \& Technology 2002;31(5):362-365.

[9] Ju YW, Jiang B, Hou QL, Wang GL. FTIR Spectroscopic study on the stress effect of compositions of macromolecular structure in tectonically deformed coals. Spectroscopy \& Spectral Analysis 2005;25(8):1216-1219.

[10] Liang YT, Tian FC, Lou HZ, Tang H. Characteristics of coal re-oxidation based on microstructural and spectral observation. International Journal of Mining Science \& Technology 2015; 25:749-754.

[11] Taraba B. Disintegration of coal as a non-oxidative source of carbon monoxide. Mining Engineer 1994;154(395):55-56.

[12] Gao SP, Zhao JT, Wang ZQ, Wang JF, Fang YT, Huang JJ. Effect of CO on fast pyrolysis behaviors of lignite. Journal of Fuel Chemistry \& Technology 2013;41(5):550-557.

[13] Hou QL, Lou Y, Song C, Han YZ, Du JG, Xu RT. Gas generation during middle-rank coal deformation and the preliminary discussion of the mechanism. Journal of China Coal Society 2014;39(8):1675-1682.

[14] Wang GH, Zhou AN. Time evolution of coal structure during low temperature air oxidation. International Journal of Mining Science \& Technology 2012;22(5):517-521.

[15] Han F, Zhang YG, Meng AH, Li QH. FTIR analysis of Yunnan lignite. Journal of China Coal Society 2014;39(11):2293-2299.

[16] Guo Y, Bustin RM. FTIR spectroscopy and reflectance of modern charcoals and fungal decayed woods: implications for studies of inertinite in coals. International Journal of Coal Geology 1998;37:29-53. 
[17] Cooke NE, Fuller OM, Gaikwad RP. FTIR spectroscopic analysis of coals and coal extracts. Fuel 1986;65(9):1254-1260.

[18] Li MF. Experimental study on kinetics and mechanisms of the main gaseous products generation from low rank coal pyrolysis.

Taiyuan, Taiyuan University of Technology 2009. 